\title{
Remote Monitoring of Cardiac Implantable Electronic Devices
}

\author{
${ }^{1}$ ATTILA ROKA, MD, PhD and ${ }^{1,2}$ MARK H. SCHOENFELD, MD \\ ${ }^{1}$ Hospital of St. Raphael, New Haven, CT \\ ${ }^{2}$ Yale University School of Medicine, New Haven, CT
}

\begin{abstract}
Pacemakers, implantable cardioverter-defibrillators, and cardiac resynchronization devices use advanced diagnostic functions to continuously monitor the patient and the device itself. Follow-up is necessary after implantation to provide individualized treatment and to detect malfunctions. Routine office visits, however, do not provide access to these data on a timely basis. Transtelephonic pacemaker follow-up has been used as an adjunct to scheduled visits. Advanced remote monitoring of implanted devices is rapidly expanding due to technological innovation in this field and promising results of large clinical trials. It has been shown to decrease patient morbidity and mortality, and to help with the management of heart failure and atrial fibrillation. The technology is widely accepted by physicians and patients alike and is more cost-effective than conventional follow-up. Ongoing studies are evaluating whether remote follow-up may guide anticoagulation for atrial fibrillation, facilitate early hospital discharge after device implantation, or completely replace routine office visits. However, lack of standardization may slow down widespread utilization of recent advances. The outlook for this technology is excellent and remote monitoring will continue to improve patient-centered, cost-effective follow-up of implanted cardiac devices.
\end{abstract}

KEYWORDS. cardiac resynchronization therapy, follow-up, pacemaker, implantable cardioverter-defibrillator, remote monitoring.
ISSN 2156-3977 (print) ISSN 2156-3993 (online)

(C) 2011 Innovations in Cardiac Rhythm Management

\section{Follow-up of implantable cardiac devices}

Patients require follow-up after implantation of a pacemaker (PM), implantable cardioverter-defibrillator (ICD), or cardiac resynchronization therapy device (CRT) to assess and adjust diagnostic, pacing, and antitachycardia functions. The frequency of follow-up is determined by multiple factors, including patient comorbidities, geographic accessibility to medical care and type of the implanted device. ${ }^{1}$ Current guidelines recommend in person follow-up within $72 \mathrm{~h}$ after implantation of any device, with the next visit at 2-12 weeks. Thereafter, in

The authors report no conflicts of interest for the published content. Manuscript received April 15, 2011, final version accepted May 23, 2011.

Address correspondence to: Mark H. Schoenfeld, MD, Clinical Professor of Medicine, Yale University School of Medicine, Director, Cardiac Electrophysiology and Pacemaker Laboratory, Hospital of Saint Raphael, 330 Orchard St, Suite \#210, New Haven, CT 06511.

E-mail: mschoenfeld@srhs.org person or remote follow-up is recommended every 312 months for pacemakers, and every 3-6 months for ICDs or CRT-defibrillators (CRT-D). Once every year, in person follow-up is required for any device, even if more frequent remote follow-up is performed. At signs of battery depletion, in person or remote follow-up every $1-3$ months is needed. ${ }^{2}$

In practice, office follow-up visits are frequently uneventful, revealing no relevant changes related to the implanted device or the patient's condition. There were an estimated 1.6 million PM and 2.1 million ICD follow-up encounters in 2007 in the USA alone, causing a significant burden on the cardiovascular workforce and contributing to increasing health-care costs.

\section{Remote monitoring systems}

The importance of pacemaker follow-up was recognized soon after these devices were introduced half a century 
ago, as early leads and generators were unreliable. After decades of technological innovation, hardware-related issues of the generators are now extremely rare; however, lead-related complications are still not uncommon (dislodgement, insulation failure, fracture etc.). Introduction of sophisticated devices, such as ICDs and CRTs, significantly increased the workload of a followup session due to the large amount of diagnostic data that needs to be interpreted and device settings that have to be optimized for the patient. However, most office follow-up visits are routine procedures that rarely require extensive changes to the settings.

The first rudimentary remote pacemaker follow-up system, transtelephonic monitoring was introduced 40 years ago. It allows the assessment of battery condition with basic sensing and pacing data. ${ }^{3}$ This communication method requires simultaneous active participation from both the patient and medical staff; however, it cannot provide data regarding advanced functions, such as arrhythmia events or pacing statistics, which are essential in the follow-up of advanced devices. ${ }^{4}$ Most major device manufacturers have recently developed and introduced remote PM/ICD/CRT monitoring systems. ${ }^{5,6}$ Although the basic concept is similar, the hardware and software for each device company is unique and the systems are only compatible within a specific product line (Figure 1).

The implanted device incorporates a short-range telemetry antenna, which communicates with the remote transmitter using radiofrequency signals, on an intermittent basis. This may either require active patient participation, such as placing a telemetry wand over the device, or may be completely automatic, when the transmission occurs at given time intervals if the transmitter is within reception range. Most companies use a configurable schedule for transmission, with an option for patient-triggered transmission. The two extremes of transmission intervals can be classified as "remote follow-up", when transmission is performed once every several months, similar to an office visit, and "remote monitoring", when transmission occurs daily, allowing more rapid detection of an adverse event. Truly continuous remote monitoring is not feasible with current battery technology as the energy consumption during the telemetry session is significantly higher than during normal device operation. The relatively low data transfer speed with the short time available for transmission (up to a few minutes, to be convenient for the patient) limits the amount of information that can be communicated. Current remote monitoring technology does not provide the complete data acquisition that can be accomplished during an office visit. Intracardiac electrogram (IEGM) is an essential part of diagnostic information, but requires large amount of data to be transmitted. However, even short segments of IEGM can be of significant diagnostic help: the RIONI study (Biotronik, Lake Oswego, OR) found that IEGMs with a mean length of $4.4 \pm 1.5 \mathrm{~s}$ were adequate to assess the

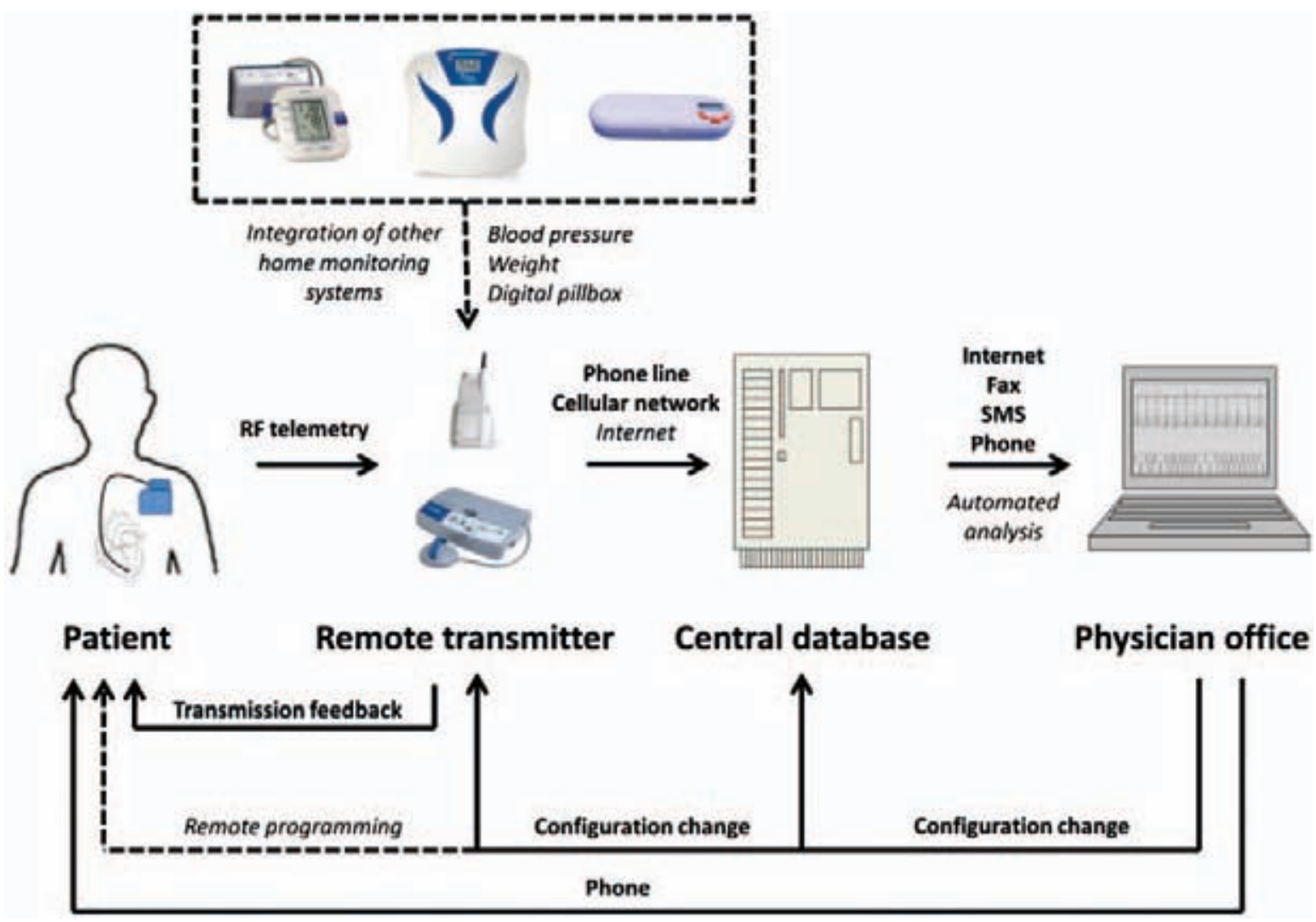

Figure 1: General set up of current remote monitoring systems. Features that are still not widely implemented or experimental are displayed in italic. Remote programming is not available currently. 
appropriateness of ICD therapy in $92 \%$ of cases and were helpful for arrhythmia classification in $93.4 \%{ }^{7}$ The small computing capacity of the implanted devices limits the use of advanced data processing methods (crunching, encryption). The communication may be intercepted and altercated; however, no significant patient safety breaches have been reported so far. ${ }^{8}$

The patient receives feedback regarding the success or failure of the transmission. Some systems may be used to gather and transmit data from different home monitoring devices (such as scales, blood pressure device, hemodynamic monitor). Future improvements may include integration with further diagnostic modalities or medication management systems (digital pillbox). The transmitter forwards data to the central databank using a phone line or cellular network. Mobile systems are preferred in active (working, travelling) patients. Transmitters using the cellular network may include roaming capability, allowing the patient to travel while being monitored.

The server of the databank performs triage of the incoming data and notifies the physician's office via internet, fax or phone message. The clinician (usually a mid-level provider) evaluates the triaged data and may notify the physician or the patient, adjust the transmission schedule, or configure alerts. Server-side data analysis with automated response may decrease the workload of the follow-up team. As the computing capacity of the database mainframe exceeds that of the implanted device, more detailed analysis of diagnostic information may be possible to improve data triage or facilitate automatic responses.

Remote reprogramming of correctable malfunctions (such as oversensing issues) may spare an office visit or avoid an adverse event (Figure 2). Despite technical feasibility, current systems do not allow remote (nevertheless automatic) reprogramming. As most implanted devices already automatically adjust their settings (such as pacing threshold management), this would be a logical expansion of an already used feature, using the greater computing capacity of a central server.

\section{Feasibility and patient safety with remote monitoring}

Most clinical studies have addressed safety and feasibility issues, as remote monitoring is a relatively new technology (Table 1). Patient and clinician acceptance was found to be high in early trials. ${ }^{9,10}$ There are significant differences between different manufacturers' systems, which makes generalization of data difficult.

The ALTITUDE registry (Boston Scientific, St. Paul, $\mathrm{MN}$ ) compared outcomes between patients followed in the device clinic only and those who also regularly transmitted remote data, on average four times a month. For the 69,556 ICD and CRT-D patients receiving remote follow-up, 1- and 5-year survival rates were higher compared with the 116,222 patients who received device follow-up in device clinics only (mortality reduction $44 \%$ with ICD, 56\% with CRT-D). The differences were not affected by patient characteristics such as age, gender, implanted device year or type, economic or educational status, although this was not a randomized study. ${ }^{11}$

Timely intervention based on early detection of deviceor patient-related issues may avoid more severe complications. Preliminary data from the ECOST trial (Biotronik) show that patients with the Medtronic Sprint Fidelis lead experienced lead fracture requiring lead replacement in $7.5 \%$ over an average of 22 month follow-up, all of these events were preceded by oversensing of noise artifacts or an abrupt rise in pacing impedance noticeable on remote transmissions (Figure 3). ${ }^{12}$ The PREFER trial (Medtronic, Mounds View, MN) compared traditional 2-month transtelephonic monitoring (with 6-month office visits) and remote transmission at 3-month intervals (with 12month office visits). More events requiring action (new onset or sustained atrial tachyarrhythmia, ventricular arrhythmias, lead or battery issues) were detected in the remote group and the mean time

to first diagnosis was shorter (incidence $45 \%$ versus $37.6 \%$, time to detection 5.7 versus 7.7 months). Sixty-six per cent of the events in the remote arm were identified remotely, compared with $2 \%$ in the control arm; conventional transtelephonic transmissions are less sensitive to pick up adverse events. ${ }^{13}$ Transtelephonic monitoring was found to be most useful to monitor battery longevity. ${ }^{3}$

Automatic interpretation of interrogated data may reduce the workload of professionals involved in followup. A rule-based data filter was generally well accepted and found to be accurate in a multicenter study. ${ }^{14}$ Automatic clinician alert triggers used with remote follow-up reduce time needed to action: the CONNECT trial (Medtronic) randomized 1997 patients and followed them at $1,3,6,9,12$, and 15 months (patients in the remote arm had only remote follow-up at months 3, 6, 9, and 12). The median time to clinical decision after a detected event was reduced from 22 days in the in-office arm to 4.6 days in the remote arm, and the mean length of stay per cardiovascular hospitalization visit decreased from 4.0 days in the in-office arm to 3.3 days. ${ }^{15}$ Only $55 \%$ of the triggered automatic alerts were transmitted successfully to the clinician due to configuration errors or patient location (the study used a land line-based system). Automated, event-based clinician alert was thus able to improve clinical outcomes even when the routine remote follow-up was not performed more frequently than the office follow-up. The ongoing REACT study (St. Jude Medical, St. Paul, MN) will address similar questions.

Increasing the time interval between office follow-up visits may be safe if adequate remote monitoring is performed. The TRUST study (Biotronik) compared remote monitoring and conventional follow-up at 3, 6, 9,12 , and 15 months after implantation. Office visits at 6 , 9 , and 12 months were performed in the remotely monitored group only if necessary based on remote data. As a result, $85.8 \%$ of these were withheld, in-office device evaluations were reduced by $45 \%$ without significantly affecting mortality $(3.4 \%$ remote versus $4.5 \%$ in conventional) or adverse event rates $(10.4 \%$ / year in both groups). At the mandatory 3-month follow-up 

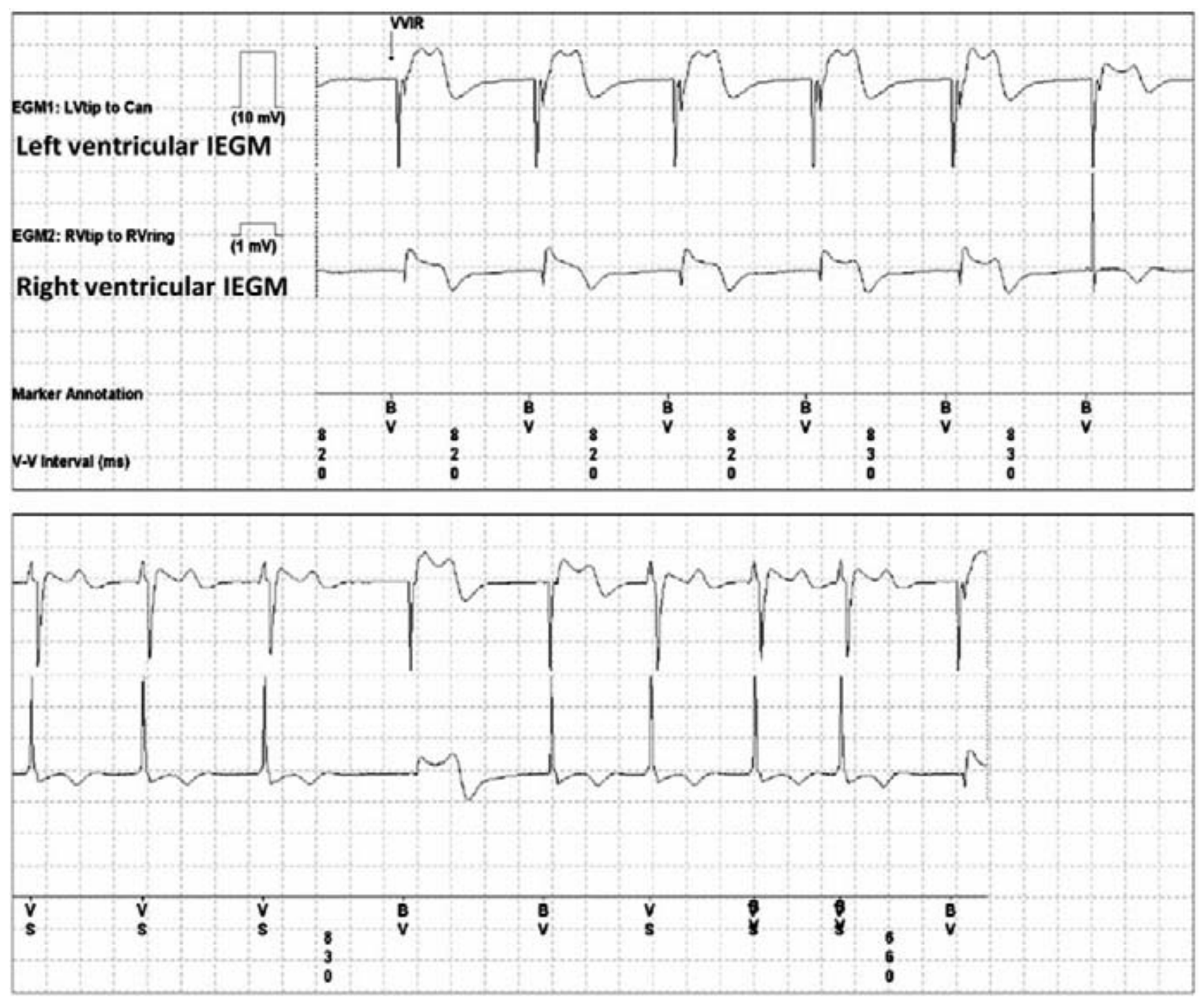

Figure 2: Remotely transmitted intracardiac electrogram (IEGM) from a patient with a cardiac resynchronization therapy defibrillator (CRT-D) and chronic atrial fibrillation (AF). Biventricular stimulation is suboptimal: the device is in VVIR pacing mode and pacing at a rate of $73 / \mathrm{min}$ in both ventricles until spontaneous atrioventricular (AV) conduction improves and inhibits ventricular pacing (beats 7-9). Pacing statistics may underestimate the amount of effective biventricular stimulation as beats 11, 13, and 14 are more consistent with spontaneous ventricular activation despite being classified as biventricular paced (beat 11) or ventricular sense response beats (13 and 14). Simple adjustment of pacing settings may resolve this issue. BV, biventricular pace; VS, ventricular sensed event.

office visit, $6.6 \%$ of patients from both groups had findings requiring action, with similar distribution: reprogramming $(78.4 \%$ versus $72.6 \%)$, antiarrhythmic medication change $(21.9 \%$ versus $29.6 \%)$, or lead or generator revision $(4.4 \%$ versus $3.2 \%)$. The frequency of unscheduled office visits was low, but higher in the remote group ( 0.78 versus $0.50 /$ year). Median time to evaluation of arrhythmic events was less in the remote group ( 2 versus 36 days). ${ }^{16}$ More device-related adverse events were observed in the remote group $(4.4 \%$ versus $1.4 \%$ ); of these $47 \%$ were asymptomatic, but $32 \%$ required surgical correction. ${ }^{17}$

Data from the InSync ICD registry (Medtronic) show that the need to re-program the device during follow-up decreases significantly 6 months after implantation and there is no need to alter device settings even after shocks in $49 \%$ of cases. ${ }^{18}$ Although there are specific device- or arrhythmia-related issues, which are best addressed by a cardiac device specialist, most patients are followed by multiple health-care providers (general cardiologist, heart failure specialist, primary care etc.), which can make office visits redundant. The ongoing ANVITE trial (Biotronik) will compare adverse event rates and quality of life measures of 12-month office ICD follow-up intervals and advanced daily remote monitoring (threshold, impedance, IEGM), with 3-month office follow-up. The VIRTUE trial (Biotronik) will investigate the efficacy and safety of daily remote monitoring with a goal to completely replace routine device office visits over a 7year follow-up period. 
Table 1: Clinical trials assessing general safety and efficacy of remote monitoring systems. Ongoing trials were accessed on www.clinicaltrials.gov

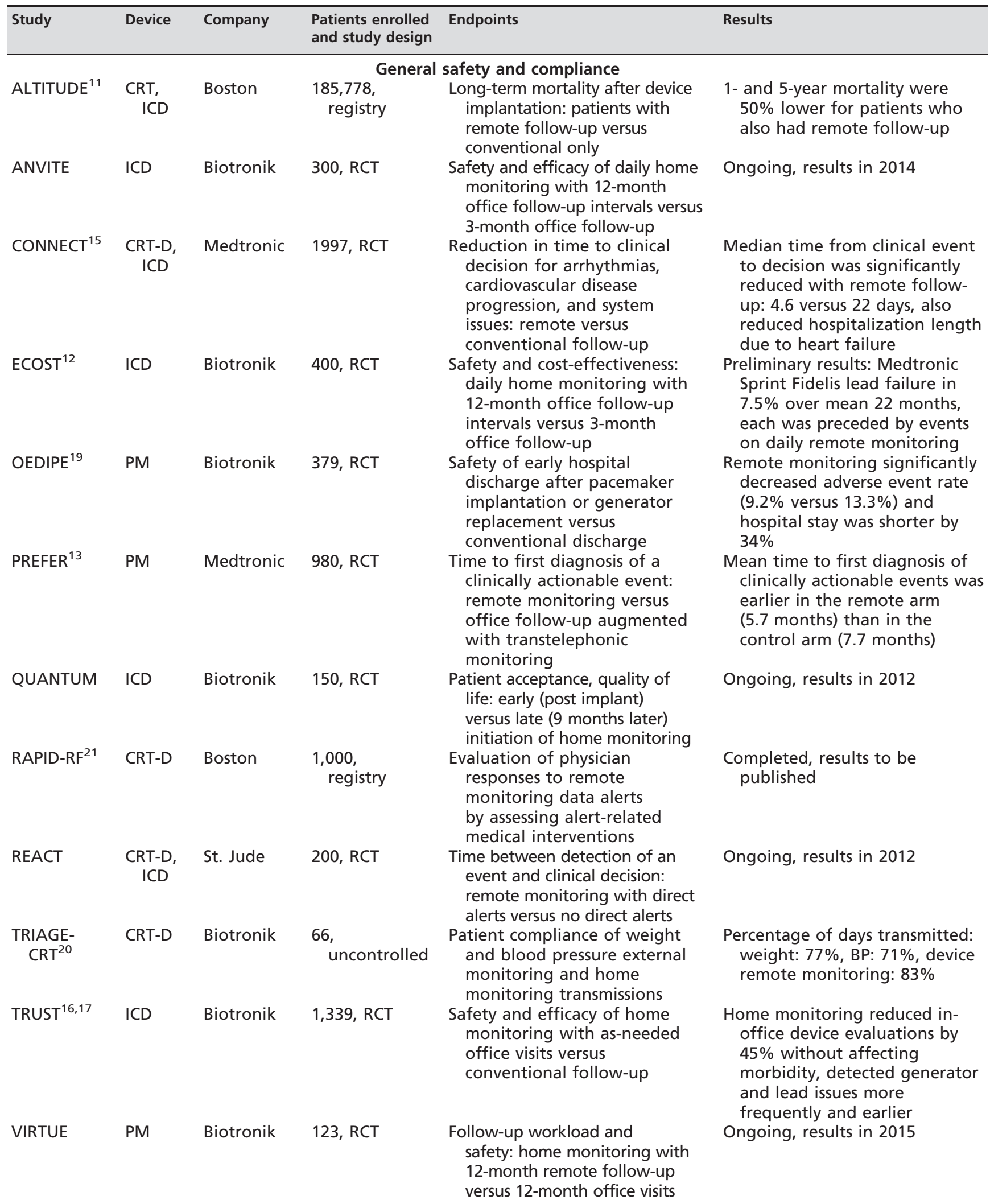

BP, blood pressure; CRT, cardiac resynchronization therapy (device); CRT-D, cardiac resynchronization therapy defibrillator; ICD, implantable cardioverter-defibrillator; PM, pacemaker; RCT, randomized controlled trial. 


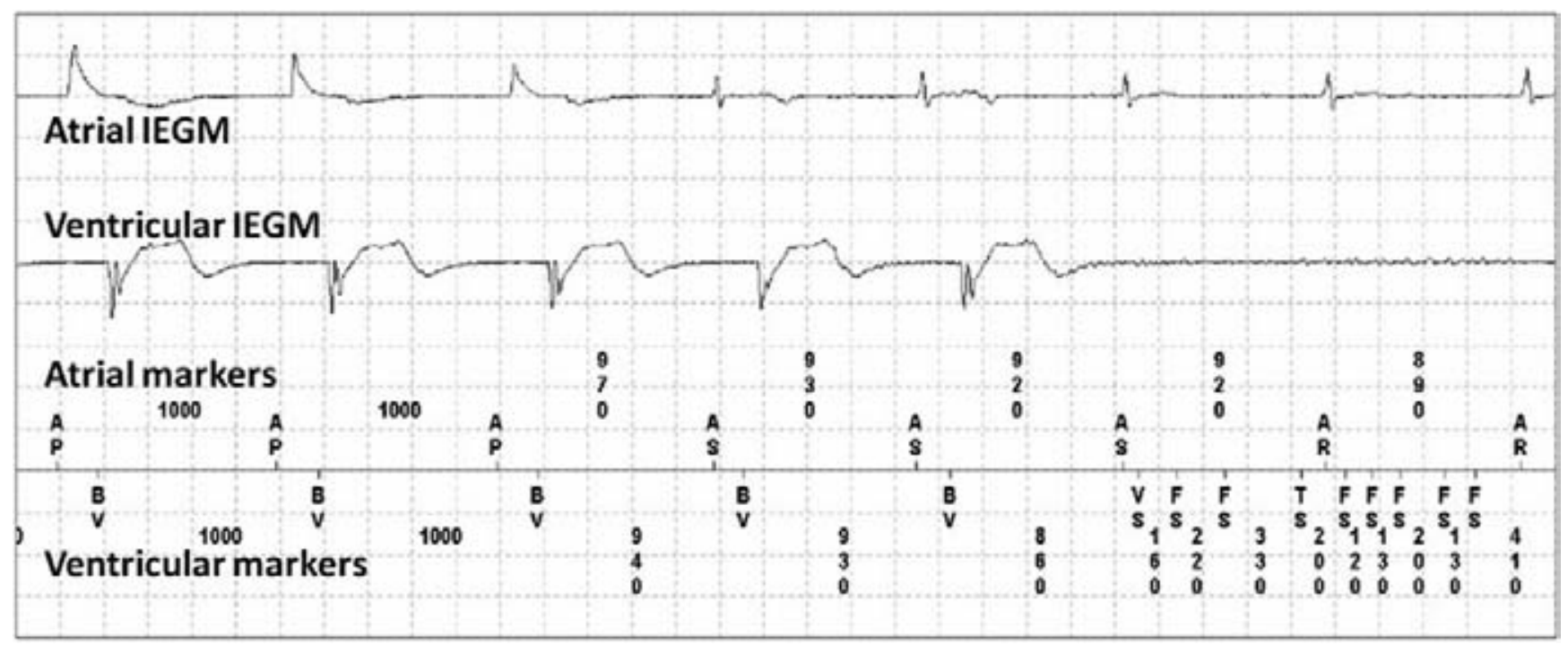

Figure 3: Intracardiac electrogram (IEGM) of an episode misclassified as non-sustained ventricular tachycardia by the cardiac resynchronization therapy defibrillator (CRT-D). There is actually loss of appropriate sensing on the ventricular channel, with oversensing of noise, caused by intermittent malfunction of the ventricular pacing/sensing/defibrillator lead. A low amplitude noise is seen on the ventricular channel after the fourth beat, which replaces the ventricular near-field signal after the fifth beat. As the defibrillator adjusts the sensitivity, noise is detected as ventricular tachycardia/ventricular fibrillation (VT/VF). This lead malfunction may manifest as intermittent loss of biventricular pacing or inadequate tachyarrhythmia therapies. IEGM is essential to diagnose this malfunction as counters are non-specific and can be misleading. AP, atrial pace; AS, atrial sensed event; AR, atrial event sensed in the refractory period; BV, biventricular pace; FS, ventricular sensed event in the ventricular fibrillation rate; TS, ventricular sensed event in the ventricular tachycardia rate; VS, ventricular sensed event.

The incidence of adverse events is higher in the immediate post-implantation period and patients are routinely observed in-hospital after the procedure. Remote monitoring may decrease the hospital stay after pacemaker implantation or generator replacement. The OEDIPE trial (Biotronik) compared patients discharged from the hospital $24 \mathrm{~h}$ after a first PM implant or 4-6 h after replacement, followed for 4 weeks with daily remote monitoring, with a control group followed for 4 weeks according to usual practices. The remote group had a $4.1 \%$ absolute risk reduction in experiencing at least one treatment-related major adverse event (such as lead issues, death, myocardial infarction, or heart failure (HF) exacerbation). By study design, the mean hospitalization duration also became shorter by $34 \% .{ }^{19}$ The QUANTUM trial (Biotronik) will compare the effects of immediate or delayed (9-month) initiation of automatic daily remote monitoring after ICD implantation on quality of life, patient perceptions, and frequency of patient-physician contacts.

Combined remote monitoring systems may provide more clinically relevant information but may require more patient interaction. The TRIAGE CRT feasibility study (Biotronik) explored the use of remote device monitoring with weight and blood pressure external telemonitoring in 66 patients with CRT-D. Patient compliance (days transmitted) was $83 \%$ for device remote monitoring and $71 \%$ for weight and blood pressure measurements over a 6-month follow-up period. ${ }^{20}$ The ongoing RAPID-RF (Boston Scientific) multicenter registry will assess a similar combined system. $^{21}$

\section{Cost-efficacy}

Comparison of cost-efficacy data is not straightforward given the significant differences in remote monitoring systems and health-care settings (Table 2). The REFORM trial (Biotronik) compared ICD remote monitoring against conventional follow-up in 115 MADIT II-like patients (27-month follow-up, 3-month remote follow-up with office visits at 3, 15, and 27 months versus 3-month office visits). There was no difference in hospitalizations and mortality, whereas the difference in potential costsavings was significant: 0.81 physician hours and 712 Euro costs saved each year per patient with remote monitoring. Office visits were reduced by $63.2 \%$ in the remote group. ${ }^{22}$ A secondary objective of the CONNECT trial (Medtronic) was to compare cardiovascular healthcare utilization between patients in the remote and inoffice arms. As the mean length of stay of cardiovascular hospitalization was shorter in the remote group, the mean savings were estimated at $\$ 1,793$ per hospitalization (\$8,114 remote versus $\$ 9,822$ in-office). ${ }^{15}$

The ongoing EuroECO (Biotronik), EVOLVO (Medtronic) and TARIFF (St. Jude Medical) studies will also compare cost-efficacy and health-care utilization endpoints. ${ }^{23}$

\section{Management of atrial fibrillation}

Atrial tachyarrhythmias are frequent causes of morbidity in PM and ICD recipients. A multivariate analysis of the MOST trial data demonstrated that the atrial high rate events recorded by pacemaker diagnostics are independent predictors of total mortality or non-fatal stroke 
Table 2: Clinical trials assessing cost-effectiveness and management of atrial fibrillation with remote monitoring systems. Ongoing trials were accessed on www.clinicaltrials.gov

\begin{tabular}{|c|c|c|c|c|c|}
\hline Study & Device & Company & $\begin{array}{l}\text { Patients enrolled } \\
\text { and study design }\end{array}$ & Endpoints & Results \\
\hline \multicolumn{6}{|c|}{ Cost-effectiveness } \\
\hline EuroEco & ICD & Biotronik & $312, \mathrm{RCT}$ & $\begin{array}{l}\text { Cost-efficacy and safety: daily home } \\
\text { monitoring with } 12-24 \text { month office follow- } \\
\text { up versus unrestricted office only follow-up }\end{array}$ & $\begin{array}{l}\text { Ongoing, results } \\
\text { in } 2012\end{array}$ \\
\hline EVOLVO $^{23}$ & $I C D$ & Medtronic & 200, RCT & $\begin{array}{l}\text { Health-care utilization, costs, device adverse } \\
\text { events and morbidity: ICD with remote } \\
\text { follow-up and 8-month office visits versus } \\
\text { 4-month office visits }\end{array}$ & Ongoing \\
\hline REFORM ${ }^{22}$ & $I C D$ & Biotronik & 115, RCT & $\begin{array}{l}\text { Cost-efficacy of home monitoring and yearly } \\
\text { office follow-up versus 3-month office } \\
\text { follow-up }\end{array}$ & $\begin{array}{l}\text { Home monitoring } \\
\text { reduces physician } \\
\text { hours and costs } \\
\text { of follow-up }\end{array}$ \\
\hline TARIFF & $I C D$ & St. Jude & $200, \mathrm{RCT}$ & $\begin{array}{l}\text { Costs, cost-effectiveness: remote monitoring } \\
\text { versus conventional follow-up } \\
\text { rial fibrillation }\end{array}$ & $\begin{array}{l}\text { Ongoing, results } \\
\text { in } 2012\end{array}$ \\
\hline EFFECT & CRT-D & Biotronik & $300, \mathrm{RCT}$ & $\begin{array}{l}\text { Mortality and morbidity with daily home } \\
\text { monitoring versus conventional follow- } \\
\text { up to manage AF and CHF, patients with } \\
\text { CRT-D and paroxysmal or persistent AF }\end{array}$ & $\begin{array}{l}\text { Ongoing, results } \\
\text { in } 2012\end{array}$ \\
\hline IMPACT $^{26}$ & $\begin{array}{l}\text { CRT-D, } \\
\text { ICD }\end{array}$ & Biotronik & 2,718, RCT & $\begin{array}{l}\text { Thromboembolic events and bleeding in } \\
\text { patients with AF managed by pre-defined } \\
\text { anticoagulation plan: home monitoring } \\
\text { versus conventional follow-up }\end{array}$ & $\begin{array}{l}\text { Ongoing, results } \\
\text { in } 2012\end{array}$ \\
\hline SETAM & PM & Biotronik & $600, \mathrm{RCT}$ & $\begin{array}{l}\text { Delay to treatment for new supraventricular } \\
\text { arrhythmia and adverse events: } \\
\text { pacemaker with telecardiology function, } \\
\text { enabled versus passive }\end{array}$ & $\begin{array}{l}\text { Ongoing, results } \\
\text { in } 2012\end{array}$ \\
\hline
\end{tabular}

\footnotetext{
AF, atrial fibrillation; BP, blood pressure; CHF, congestive heart failure; CRT, cardiac resynchronization therapy (device); CRT-D, cardiac resynchronization therapy defibrillator; ICD, implantable cardioverter-defibrillator; LVEF, left ventricular ejection fraction; PM, pacemaker; RCT, randomized controlled trial.
}

(hazard ratio $(\mathrm{HR})=2.79$ ) and chronic atrial fibrillation $(\mathrm{HR}=5.93)$ in patients with sinus node dysfunction. ${ }^{24}$ Remote monitoring provides access to diagnostic device data on a timely basis, which may guide early intervention (Figure 4, Table 2). The TRENDS observational study (Medtronic) showed that thromboembolic risk was proportional to the atrial tachycardia/atrial fibrillation (AT/AF) burden, defined as the longest total AT/AF duration on any given day during a 30-day period. Twothousand, four-hundred and eighty-six patients with PMs or ICDs and CHADS2 score $\geqslant 1$ were followed: at a mean follow-up of 1.4 years, annualized thromboembolic risk was $1.1 \%$ for zero-, $1.1 \%$ for low- $(<5.5 \mathrm{~h})$, and $2.4 \%$ for high- $(>5.5 \mathrm{~h})$ burden subsets. ${ }^{25}$

The IMPACT trial (Biotronik) investigates whether therapeutic action based on atrial high rate episode information can impact stroke incidence: initiation and termination of anticoagulation with coumadin is managed by a predefined plan in case an episode longer than $48 \mathrm{~h}$ is detected, potentially reducing the risk of stroke and systemic embolism, while avoiding the bleeding risks of prolonged anticoagulation. Patients with dual chamber
ICD or CRT-D, CHADS2 score $\geqslant 1$, without history of permanent $\mathrm{AF}$ or stroke and with no contraindications for anticoagulation are enrolled and undergo continuous daily remote surveillance. Primary endpoints are stroke, systemic embolism and major bleeding, follow-up duration is 3 years. ${ }^{26}$ The SETAM trial (Biotronik) will compare the delay to implement treatment for atrial tachyarrhythmias in patients with dual chamber pacemakers, sinus rhythm and CHADS2 score $\geqslant 2$, followed by remote monitoring versus conventional manner. The EFFECT trial (Biotronik) will assess the benefits of early optimization of CRT via daily remote monitoring, in addition to investigating the role of remote monitoring of atrial tachyarrhythmias in subjects with CRT-D and paroxysmal or persistent AF. The ongoing CASTLE-AF (Biotronik) uses daily remote monitoring in ICD patients with HF to compare the effect of radiofrequency catheter ablation on mortality and morbidity with that of conventional treatment.

Pacing may be attempted to prevent an AF episode if a predisposing condition is identified. Several atrial pacing algorithms were developed to suppress AF episodes by pacing at a rate that is slightly above the intrinsic rate, 
V. rate during AT/AF (bpm)

maxiday

- avg/day

\section{\% Pacing/day \\ - Atrial \\ - Ventricular}

Avg V. rate (opm)

- Day

Patient activity hours/day
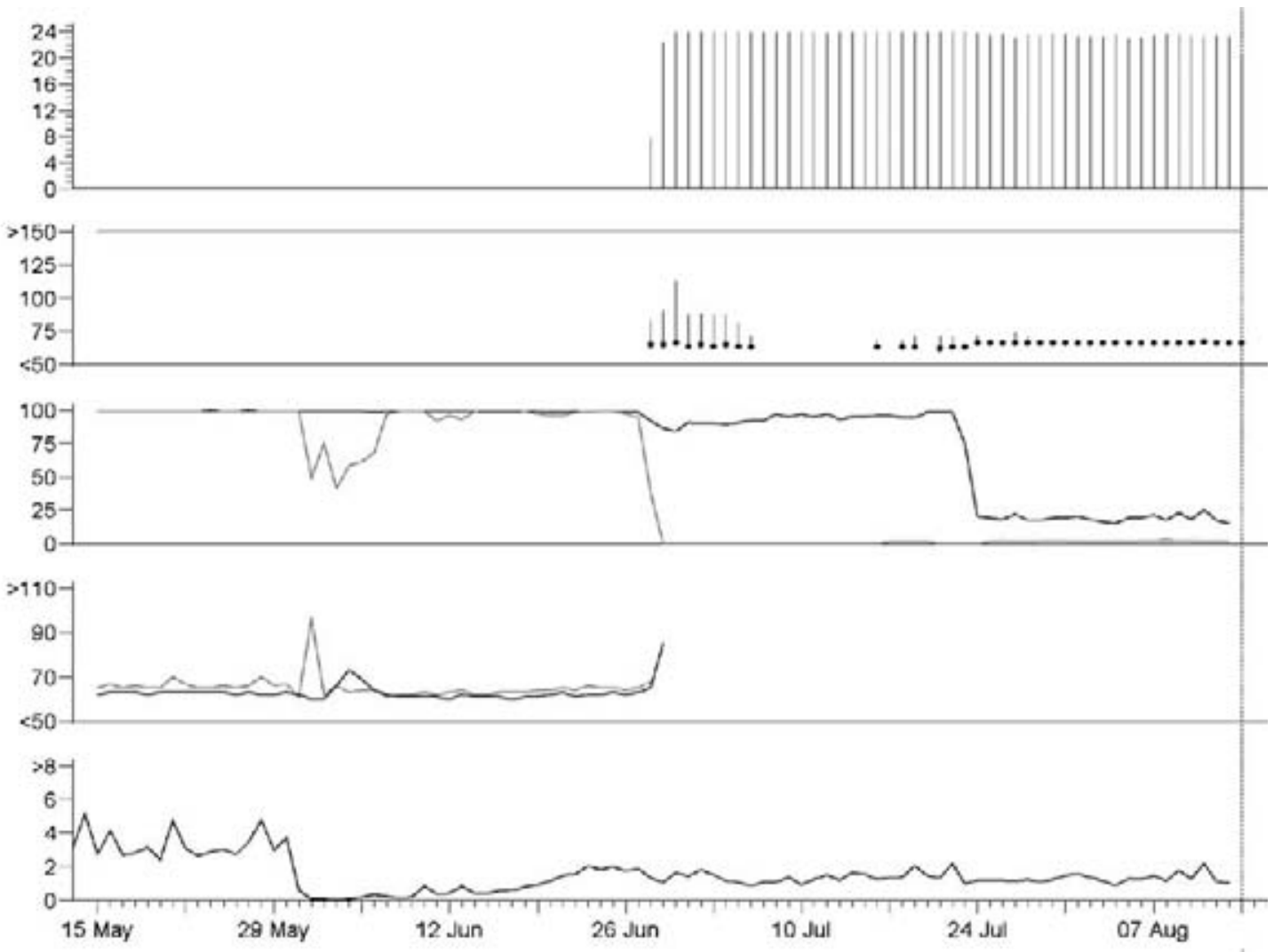

Optivol fuid index
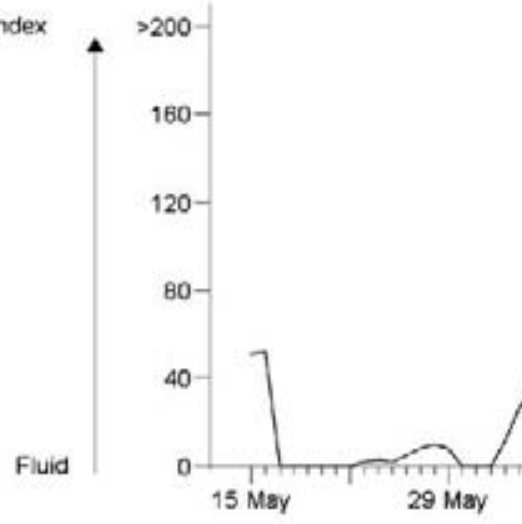

26 Jun

24 Jul

07 Aug

Fluid

$29 \mathrm{May}$

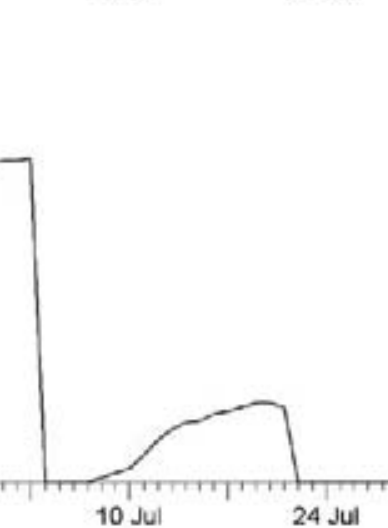

24 Jul

Figure 4: Remote transmission of long-term implantable cardioverter-defibrillator (ICD) follow-up data. A transient decrease in the amount of atrial pacing, with increased ventricular pacing and persistent decrease in daily patient activity may be observed, which is followed by worsening intrathoracic fluid accumulation. These events preceded the onset of persistent atrial fibrillation by 1 month.

adjusting pacing rate for physical activity, shortening post-extrasystolic pauses or terminating atrial tachycardias with antitachycardia pacing (ATP). Unfortunately, data regarding their efficacy are still controversial. ${ }^{27,28}$ Patients with low percentages of atrial pacing during conventional dual chamber pacing seem to benefit more from the activation of preventive algorithms. ${ }^{29}$

\section{Heart failure}

Early detection of hemodynamic changes or fluid overload may help to guide interventions to avoid hospitalizations due to HF exacerbation. Remote monitoring of symptoms, weight, and blood pressure was cost-saving in a meta-analysis of 21 European multidisciplinary HF management trials (5,715 patients, 3001,000 Euros saved per patient), decreased the number of hospitalizations by $30 \%$, and provided a gain of 0.06 quality-adjusted life-years per patient. ${ }^{30}$ Dedicated implantable HF devices provide additional data with continuous pressure and/or volume status monitoring. The CHAMPION trial (CardioMEMS, Atlanta, GA) showed that wireless monitoring of an implantable pulmonary artery pressure monitor in patients with NYHA class III HF decreased the rate of HF-related 
hospitalization by $36 \%$ over a 15 -month follow-up period. Rate of system-related complications was only $1.4 \%{ }^{31}$ Integration of similar HF monitoring systems, either implanted or external, may provide additional benefits for patients with implanted arrhythmia devices. Patients who transmitted weight and blood pressure data weekly in the subgroup of CRT-D recipients in the ALTITUDE registry had the lowest mortality. ${ }^{11}$ The results of the randomized COMPASS-HF trial (Medtronic) were less convincing: $8 \%$ of 274 NYHA class III-IV HF patients with implantable hemodynamic monitors encountered systemrelated complications, and the rate of HF-related events did not decrease significantly in the remotely monitored group (21\%). However, rate of $\mathrm{HF}$ hospitalizations decreased by $36 \% .^{32}$ The REDUCE-HF trial (Medtronic) will evaluate the safety and effectiveness of an implantable hemodynamic monitor (IHM), and its combination with ICD $^{33}$ (Table 3).

Implanted devices may provide data on intrathoracic impedance, which correlates with fluid status and can thus give early warning of fluid overload. Retrospective analysis of 123 patients with CRT or ICD in the HOMECare Phase 0 registry (Biotronik) showed an increase in mean heart rate at rest and daily mean heart rate within 7 days preceding HF hospitalization in $70 \%$ of such events. Similarly, a decrease in the percentage of CRT was observed in $43 \%$ and a reduction in the patients' daily activity in $30 \% .{ }^{34}$ The HomeCARE II and IN-TIME studies (Biotronik) will further investigate the role of daily intrathoracic impedance measurement and remote monitoring in patients with CRT-D or ICD in order to develop algorithms for device-based early detection and warning of HF deterioration accompanied by pulmonary congestion. ${ }^{35}$ The MORE-CARE and OPTILINK-HF studies (Medtronic) will analyze if remote monitoring of ICD and CRT-D devices with intrathoracic impedance monitoring and automated physician alarm trigger in case of fluid accumulation will affect the mean time between event onset time and clinical decision, mortality, morbidity, and total health-care system utilization. ${ }^{36}$

CRT requires effective biventricular stimulation with optimal timing (Figure 5). Electrogram-based algorithms have been developed for atrioventricular and ventriculoventricular delay optimization and are currently being investigated in large clinical trials (SMART-AV, Boston Scientific and QuickOpt, St. Jude Medical). ${ }^{37,38}$ Monitoring the stroke volume via intracardiac impedance measurement with conventional pacemaker electrodes may also help optimization of the timing intervals; however, this method is still experimental. ${ }^{39}$

\section{Prevention of ventricular arrhythmia recurrence}

ICD discharges adversely affect quality of life. ${ }^{40}$ Shocks are frequent even in the primary prevention population: $33.2 \%$ of patients receive at least one shock over a median of 45.5 months. Both appropriate and inappropriate shocks are associated with a significant increase in the subsequent risk of death ( $\mathrm{HR}=5.68$ and 1.98 , consecutively), mostly caused by progressive HF. ${ }^{41}$ The ALTITUDE registry data showed less, but still significant risk: appropriate and inappropriate shocks for ICD had a HR of 2.62 . Appropriate shocks for CRT recipients had a HR of 2.09, whereas non-tachyarrhythmia reasons (noise and oversensing) were not associated with significantly increased risk of death in this group, although the sample size was small. ${ }^{11}$ As most adjuvant treatments (antiarrhythmic therapy, ablation, arrhythmia prevention pacing algorithms) may have significant side effects or high cost, careful risk-assessment for ventricular tachycardia/ fibrillation (VT/VF) recurrence is essential. Early detection of high-risk conditions, such as increasing frequency and complexity of premature ventricular contractions (PVCs), short-long-short (SLS) PVC patterns, and increasing baseline heart rate, may help to guide therapy. Unfortunately, only a minority of VF episodes had such specific initiation patterns in the PainFree Rx II and EnTrust trials: 30\% of VT/VF episodes were preceded by SLS cycles, part of these were VF events permitted or facilitated by pacing. ${ }^{42} \mathrm{VT}$, which occurs more commonly and may be more responsive to ATP, was initiated by a late PVC in $85 \%$, early PVC in $13 \%$, and SLS sequence in $2 \%$, the pattern of initiation was similar for both monomorphic and polymorphic VTs in a study. ${ }^{43}$ The initiating sequences in non-ischemic cardiomyopathy are less well known. In survivors of idiopathic VF, the initiating PVCs seem to mostly have short coupling intervals, without pause dependency. ${ }^{44}$

A reliable predictor of an imminent episode of VT/VF would have clinical utility if the device were capable of notifying the physician via the remote monitoring system or to provide preventive therapy. Such a predictor was tested in a test set of saved ICD IEGM records. With the analysis of heart rate and specific acceleration patterns in sinus rhythm in a 1.8-h time interval preceding a VT/VF event, sensitivity of $53-83 \%$ and specificity of $57-91 \%$ were achieved. ${ }^{45}$

Intracardiac T wave alternans (TWA) is a marker of dynamic electrical instability of ventricular myocardium similar to ECG microvolt TWA. The concordance of these measurements was $87 \%$ in a study of 68 patients, the positive predictive value for VT/VF in 1 year was $14 \%$ for intracardiac TWA and $17 \%$ for surface MTWA, negative predictive value was $82 \%$ at 4 years for both. ${ }^{46}$ TWA may be a dynamic phenomenon: a study of 28 ICD patients showed that TWA increased before spontaneous VT/VF episodes, but not before supraventricular arrhythmias-this could be easily monitored continuously with the implanted device. ${ }^{47}$ Increasing incidence of non-sustained ventricular tachycardia (NSVT) may also be a sign of electrical instability. The length, but not the rate, of NSVTs on 24-h ambulatory ECG was a predictor of major arrhythmic events in non-ischemic patients in the MACAS study. ${ }^{48}$ Further studies are needed to investigate whether the results are applicable to the general ICD population or if NSVT suppression would change the risk.

The deleterious effects of right ventricular pacing are well known from previous studies, such as DAVID. ${ }^{49}$ Biventricular stimulation, on the contrary, may decrease the risk of $\mathrm{VT} / \mathrm{VF}^{50}$ Higher atrial pacing percentage was associated with an increased incidence of atrial 
Table 3: Clinical trials assessing the efficacy of remote monitoring systems to manage heart failure. Ongoing trials were accessed on www.clinicaltrials.gov

\begin{tabular}{|c|c|c|c|c|c|}
\hline Study & Device & Company & $\begin{array}{l}\text { Patients enrolled } \\
\text { and study design }\end{array}$ & Endpoints & Results \\
\hline \multicolumn{6}{|c|}{ Heart failure } \\
\hline CHAMPION $^{31}$ & IHM & CardioMEMS & $\begin{array}{l}\text { 550, } \\
\text { RCT }\end{array}$ & $\begin{array}{l}\text { HF-related hospitalization, } \\
\text { freedom from device and } \\
\text { system-related complications: } \\
\text { IHM with remote monitoring } \\
\text { versus no monitoring after } \\
\text { implant }\end{array}$ & $\begin{array}{l}30 \% \text { reduction in HF } \\
\text { hospitalizations at } \\
6 \text { months, } 36 \% \text { at mean } \\
15 \text {-month follow-up with } \\
\text { IHM+remote monitoring. } \\
\text { Device or system-related } \\
\text { complications only in } \\
1.4 \%\end{array}$ \\
\hline $\begin{array}{l}\text { COMPASS- } \\
\mathrm{HF}^{32}\end{array}$ & IHM & Medtronic & $\begin{array}{l}\text { 274, } \\
\text { RCT }\end{array}$ & $\begin{array}{l}\text { Freedom from system-related } \\
\text { complications, freedom from } \\
\text { pressure-sensor failure, } \\
\text { reduction in the rate of HF- } \\
\text { related events: patients with } \\
\text { implantable hemodynamic } \\
\text { monitors, treatment guided by } \\
\text { remote monitoring versus no } \\
\text { monitoring data }\end{array}$ & $\begin{array}{l}\text { HF-related events did not } \\
\text { differ significantly. Risk } \\
\text { of HF-hospitalization was } \\
36 \% \text { lower in the } \\
\text { IHM+remote monitoring } \\
\text { group }\end{array}$ \\
\hline $\begin{array}{l}\text { HOMECARE } \\
\text { Phase } 0^{34}\end{array}$ & $\begin{array}{l}\text { CRT-P, } \\
\text { CRT-D, } \\
\text { ICD }\end{array}$ & Biotronik & $\begin{array}{l}\text { 123, } \\
\text { registry }\end{array}$ & $\begin{array}{l}\text { Daily home monitoring to } \\
\text { monitor HF patients with } \\
\text { ICD or CRT }\end{array}$ & $\begin{array}{l}\text { Before HF hospitalization, } \\
70 \% \text { had increase in mean } \\
\text { heart rate at rest and in } \\
\text { mean heart rate over } \\
24 \mathrm{~h} \text { in the preceding } \\
7 \text { days, a decrease in the } \\
\text { percentage of CRT was } \\
\text { observed in } 43 \% \text {, } \\
\text { reduction in the daily } \\
\text { activity was in } 30 \%\end{array}$ \\
\hline HomeCARE II & $\begin{array}{l}\text { CRT-D, } \\
\text { ICD }\end{array}$ & Biotronik & $\begin{array}{l}\text { 300, } \\
\text { uncontrolled }\end{array}$ & $\begin{array}{l}\text { Performance of intrathoracic } \\
\text { impedance measurement with } \\
\text { daily monitoring to predict HF } \\
\text { exacerbations }\end{array}$ & Ongoing, results in 2011 \\
\hline Optilink-HF & CRT-D, ICD & Medtronic & $1,000, \mathrm{RCT}$ & $\begin{array}{l}\text { Mortality or CV hospitalization: } \\
\text { remote monitoring of device } \\
\text { and intrathoracic impedance } \\
\text { versus standard follow-up }\end{array}$ & Ongoing, results in 2013 \\
\hline REDUCE-HF ${ }^{33}$ & ICD w/PRM & Medtronic & 1,300, RCT & $\begin{array}{l}\text { Freedom from system-related } \\
\text { complications, reduction of } \\
\text { heart failure events: ICD+IHM } \\
\text { with remote monitoring } \\
\text { versus control }\end{array}$ & Ongoing, results in 2011 \\
\hline
\end{tabular}

CRT, cardiac resynchronization therapy (device); HF, heart failure; ICD, implantable cardioverter-defibrillator; IHM, implantable hemodynamic monitor; PM, pacemaker; PRM, pressure monitoring; RCT, randomized controlled trial.

tachyarrhythmias and with respect to dual chamber pacing, a ratio of paced atrial beats $\geqslant 48 \%$ combined with a ratio of paced ventricular beats $>40 \%$ was associated with an increased probability for VT in a prospective trial. ${ }^{51}$ Pacing interventions, such as application of a rate smoothing algorithm can be of importance to prevent episodes of torsade de pointes in long QT patients; however, data are mostly from small clinical studies. ${ }^{52}$ Rate smoothing has been used to prevent ventricular arrhythmia in the VAST study: with rate smoothing, 23\% of patients experienced a reduction in arrhythmias, 23\% saw an increase and the remaining $54 \%$ had no difference and no individually useful predictors were found. ${ }^{53}$ Pacing algorithms may not be effective if the 

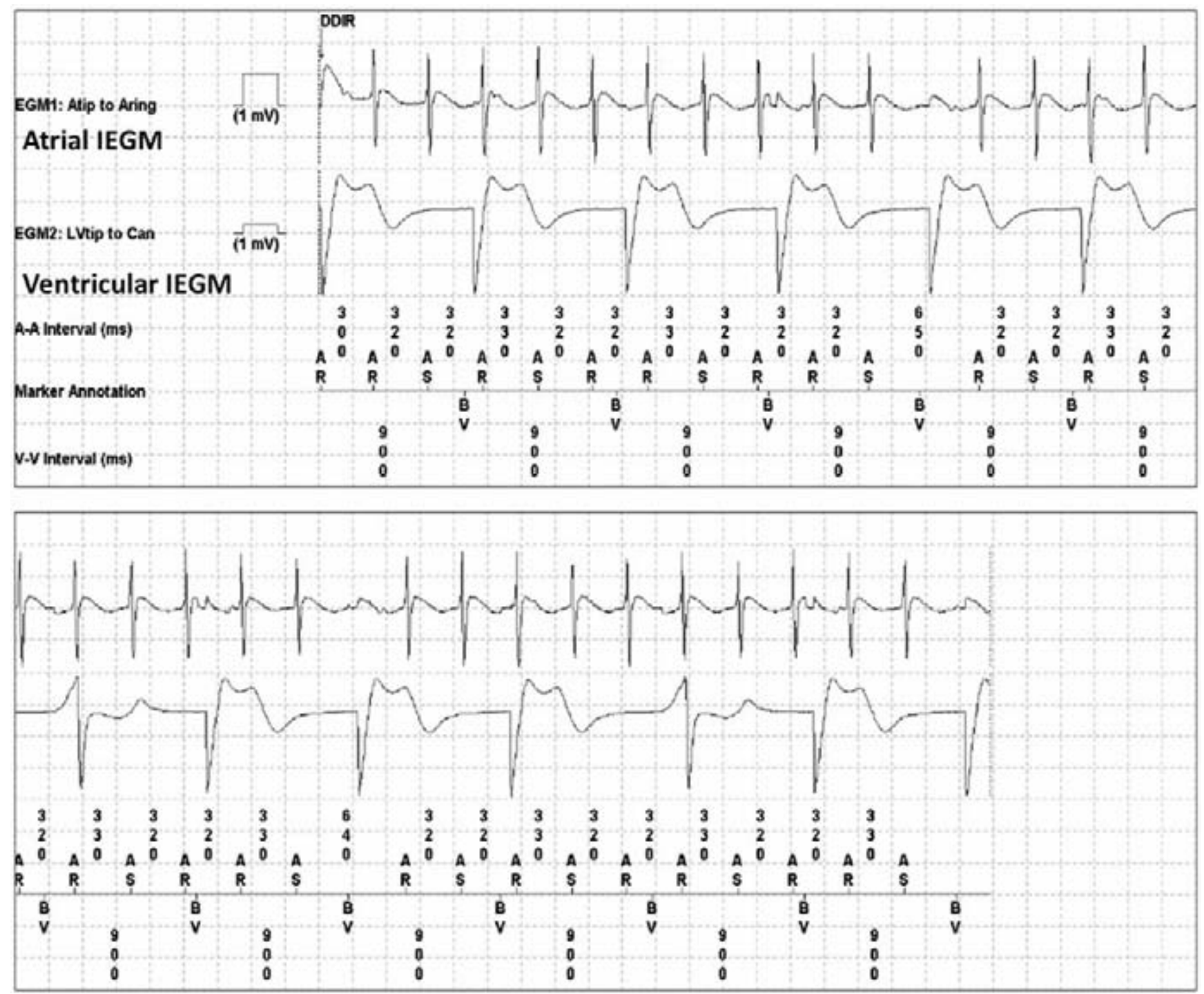

Figure 5: Intracardiac electrogram (IEGM) snapshot of a routine remote monitoring transmission. The patient has a cardiac resynchronization therapy defibrillator (CRT-D) and is in atrial flutter with complete atrioventricular block. The ventricular rate is biventricular paced in DDIR mode at $67 / \mathrm{min}$. The morphology of the ventricular signal is not uniform despite regular pacing: beats 7 and 11 have a slurred onset. This is most consistent with intermittent loss of capture in one of the paced ventricles. However, this is unrecognized by the device as there are no ventricular sensed events, but may still be responsible for suboptimal CRT. There is occasional undersensing of atrial signals due to atrial blanking after ventricular pacing-this has no consequences in this patient. AS, atrial sensed event; AR, atrial event sensed in the refractory period; BV, biventricular pace.

VT/VF is initiated by a single PVC without pausedependency and the proarrhythmic potential must not be neglected.

\section{Conclusion}

Utilization of remote monitoring is rapidly expanding based on encouraging data from large clinical trials; however, lack of standardization is still a significant barrier to widespread acceptance of results. Completely automated mobile systems, instant transmission in case of an adverse event, live IEGM monitoring, remote programming, patient alert with geographic localization, and integration with other patient care/diagnostic modalities may further enhance the efficacy and can be incorporated into existing systems with little additional development. For implanted devices without remote monitoring capabilities, transtelephonic follow-up will remain a useful adjunct to office follow-up. The huge amount of data already obtained from clinical studies may be used develop risk-stratification models and test algorithms to predict future arrhythmia or HF events.

The outlook for this technology is excellent and further innovation will help to improve patient-centered, costeffective follow-up of implanted cardiac devices. 


\section{References}

1. Epstein AE, Dimarco JP, Ellenbogen KA, Estes NAM3, Freedman RA, Gettes LS, et al. ACC/AHA/HRS 2008 guidelines for Device-Based Therapy of Cardiac Rhythm Abnormalities: executive summary. Heart Rhythm 2008; 5: 934-955.

2. Wilkoff BL, Auricchio A, Brugada J, Cowie M, Ellenbogen KA, Gillis AM, et al. HRS/EHRA expert consensus on the monitoring of cardiovascular implantable electronic devices (CIEDs): description of techniques, indications, personnel, frequency and ethical considerations. Heart Rhythm 2008; 5: 907-925.

3. Schoenfeld MH. Transtelephonic versus remote monitoring of cardiovascular implantable electronic devices: is one approach to be preferred? J Am Coll Cardiol 2009; 54: 2020 2022.

4. Schoenfeld MH, Markowitz HT. Device follow-up in the age of automaticity. Pacing Clin Electrophysiol 2000; 23: 803806.

5. Burri H, Senouf D. Remote monitoring and follow-up of pacemakers and implantable cardioverter defibrillators. Europace 2009; 11: 701-709.

6. Schoenfeld MH, Reynolds DW. Sophisticated remote implantable cardioverter-defibrillator follow-up: a status report. Pacing Clin Electrophysiol 2005; 28: 235-240.

7. Perings C, Bauer WR, Bondke H, Mewis C, James M, Böcker $\mathrm{D}$, et al. Remote monitoring of implantable-cardioverter defibrillators: results from the Reliability of IEGM Online Interpretation (RIONI) study. Europace 2011; 13: 221-229.

8. Halperin D, Heydt-Benjamin TS, Ransford B, Clark SS, Defend B, Morgan W, et al. Pacemakers and implantable cardiac defibrillators: software radio attacks and zeropower defenses. Proceedings of the 2008 IEEE Symposium on Security and Privacy 2008; 1: 129-142.

9. Schoenfeld MH, Compton SI, Mead RH, Weiss DN Sherfesee L, Englund J, Mongeon LR. Remote monitoring of implantable cardioverter defibrillators: a prospective analysis. Pacing Clin Electrophysiol 2004; 27: 757-763.

10. Marzegalli M, Lunati M, Landolina M, Perego GB, Ricci RP, Guenzati G, et al. Remote monitoring of CRT-ICD: the multicenter Italian CareLink evaluation--ease of use, acceptance, and organizational implications. Pacing Clin Electrophysiol 2008; 31: 1259-1264.

11. Saxon LA, Hayes DL, Gilliam FR, Heidenreich PA, Day J, Seth $\mathrm{M}$, et al. Long-term outcome after ICD and CRT implantation and influence of remote device follow-up: the ALTITUDE survival study. Circulation 2010; 122: 23592367.

12. Guédon-Moreau L, Chevalier P, Marquié C, Kouakam C, Klug D, Lacroix D, et al. Contributions of remote monitoring to the follow-up of implantable cardioverter-defibrillator leads under advisory. Eur Heart J 2010; 31: 2246-2252.

13. Crossley GH, Chen J, Choucair W, Cohen TJ, Gohn DC, Johnson WB, et al. Clinical benefits of remote versus transtelephonic monitoring of implanted pacemakers. J Am Coll Cardiol 2009; 54: 2012-2019.

14. Sinha A, Koos R, Markus KU, Diem BH, Urbaszek A, Hanrath P, Stellbrink C. Multicentre evaluation of a rulebased data filter for home monitoring of implanted cardioverter defibrillators. J Telemed Telecare 2006; 12: 97 102.

15. Crossley GH, Boyle A, Vitense H, Chang Y, Mead RH. The CONNECT (Clinical Evaluation of Remote Notification to Reduce Time to Clinical Decision) Trial The Value of Wireless Remote Monitoring With Automatic Clinician Alerts. J Am Coll Cardiol 2011; 8: 1181-1189.
16. Varma N, Epstein AE, Irimpen A, Schweikert R, Love C. Efficacy and safety of automatic remote monitoring for implantable cardioverter-defibrillator follow-up: the Lumos-T Safely Reduces Routine Office Device Follow-up (TRUST) trial. Circulation 2010; 122: 325-332.

17. Varma N, Michalski J, Epstein AE, Schweikert R. Automatic remote monitoring of implantable cardioverter-defibrillator lead and generator performance: the Lumos-T Safely RedUceS RouTine Office Device Follow-Up (TRUST) trial. Circ Arrhythm Electrophysiol 2010; 3: 428-436.

18. Lunati M, Gasparini M, Santini M, Landolina M, Perego GB, Pappone C, et al. Follow-up of CRT-ICD: implications for the use of remote follow-up systems. Data from the InSync ICD Italian Registry. Pacing Clin Electrophysiol 2008; 31: 3846.

19. Halimi F, Clémenty J, Attuel P, Dessenne X, Amara W. Optimized post-operative surveillance of permanent pacemakers by home monitoring: the OEDIPE trial. Europace 2008; 10: 1392-1399.

20. http:/ / clinicaltrials.gov/ct2/show/results/NCT00395642? sect $=$ X3605. Accessed on April 14, 2011.

21. Saxon LA, Boehmer JP, Neuman S, Mullin CM. Remote Active Monitoring in Patients with Heart Failure (RAPIDRF): design and rationale. J Card Fail 2007; 13: 241-246.

22. Elsner CH, Sommer P, Piorkowski C, Taborsky M, Neuser $\mathrm{H}$, Bytesnik J, et al. A prospective multicenter comparison trial of home monitoring against regular follow-up in MADIT II patients: additional visits and cost impact. Comput Cardiol 2006; 33: 241-244.

23. Marzegalli M, Landolina M, Lunati M, Perego GB, Pappone A, Guenzati $G$, et al. Design of the evolution of management strategies of heart failure patients with implantable defibrillators (EVOLVO) study to assess the ability of remote monitoring to treat and triage patients more effectively. Trials 2009; 10: 42.

24. Glotzer TV, Hellkamp AS, Zimmerman J, Sweeney MO, Yee $\mathrm{R}$, Marinchak R, et al. Atrial high rate episodes detected by pacemaker diagnostics predict death and stroke: report of the Atrial Diagnostics Ancillary Study of the MOde Selection Trial (MOST). Circulation 2003; 107: 1614-1619.

25. Glotzer TV, Daoud EG, Wyse DG, Singer DE, Ezekowitz MD, Hilker C, et al. The relationship between daily atrial tachyarrhythmia burden from implantable device diagnostics and stroke risk: the TRENDS study. Circ Arrhythm Electrophysiol 2009; 2: 474-480.

26. Ip J, Waldo AL, Lip GYH, Rothwell PM, Martin DT, Bersohn MM, et al. Multicenter randomized study of anticoagulation guided by remote rhythm monitoring in patients with implantable cardioverter-defibrillator and CRT-D devices: Rationale, design, and clinical characteristics of the initially enrolled cohort The IMPACT study. Am Heart J 2009; 158: 364-370.

27. Lee MA, Weachter R, Pollak S, Kremers MS, Naik AM, Silverman $\mathrm{R}$, et al. The effect of atrial pacing therapies on atrial tachyarrhythmia burden and frequency: results of a randomized trial in patients with bradycardia and atrial tachyarrhythmias. J Am Coll Cardiol 2003; 41: 1926-1932.

28. Padeletti L, Santini M, Boriani G, Botto G, Gulizia M, Molon $\mathrm{G}$, et al. Long-term reduction of atrial tachyarrhythmia recurrences in patients paced for bradycardia-tachycardia syndrome. Heart Rhythm 2005; 2: 1047-1057.

29. Ricci R, Pignalberi C, Disertori M, Capucci A, Padeletti L, Botto G, et al. Efficacy of a dual chamber defibrillator with atrial antitachycardia functions in treating spontaneous atrial tachyarrhythmias in patients with life-threatening ventricular tachyarrhythmias. Eur Heart J 2002; 23: 14711479 . 
30. Klersy C, De Silvestri A, Gabutti G, Raisaro A, Curti M, Regoli F, Auricchio A. Economic impact of remote patient monitoring: an integrated economic model derived from a meta-analysis of randomized controlled trials in heart failure. Eur J Heart Fail 2011; 13(4): 450-459.

31. Abraham WT, Adamson PB, Bourge RC, Aaron MF, Costanzo MR, Stevenson LW, et al. Wireless pulmonary artery haemodynamic monitoring in chronic heart failure: a randomised controlled trial. Lancet 2011; 377: 658-666.

32. Bourge RC, Abraham WT, Adamson PB, Aaron MF, Aranda JMJ, Magalski A, et al. Randomized controlled trial of an implantable continuous hemodynamic monitor in patients with advanced heart failure: the COMPASS-HF study. J Am Coll Cardiol 2008; 51: 1073-1079.

33. Adamson PB, Conti JB, Smith AL, Abraham WT, Aaron MF, Aranda JMJ, et al. Reducing events in patients with chronic heart failure (REDUCEhf ) study design: continuous hemodynamic monitoring with an implantable defibrillator. Clin Cardiol 2007; 30: 567-575.

34. Ellery S, Pakrashi T, Paul V, Sack S. Predicting mortality and rehospitalization in heart failure patients with home monitoring--the Home CARE pilot study. Clin Res Cardiol 2006;95 Suppl 3: III29-35.

35. Arya A, Block M, Kautzner J, Lewalter T, Mörtel H, Sack S, et al. Influence of Home Monitoring on the clinical status of heart failure patients: Design and rationale of the IN-TIME study. Eur J Heart Fail 2008; 10: 1143-1148.

36. Burri H, Quesada A, Ricci RP, Boriani G, Davinelli M, Favale S, et al. The MOnitoring Resynchronization dEvices and CARdiac patiEnts (MORE-CARE) study: rationale and design. Am Heart J 2010; 160: 42-48.

37. SteinKM, EllenbogenKA, GoldMR, LemkeB, LozanoIF, MittalS, et al/ SmartDelay determined AV optimization: a comparison of AV delay methods used in cardiac resynchronization therapy (SMART-AV): rationale and design. Pacing Clin Electrophysiol 2010; 33: 54-63.

38. Abraham WT, Gras D, Yu CM, Guzzo L, Gupta MS. Rationale and design of a randomized clinical trial to assess the safety and efficacy of frequent optimization of cardiac resynchronization therapy: the Frequent Optimization Study Using the QuickOpt Method (FREEDOM) trial. Am Heart J 2010; 159: 944-948.

39. Bocchiardo $M$, Meyer zu Vilsendorf D, Militello C, Lippert M, Czygan G, Gaita F, et al. Intracardiac impedance monitors stroke volume in resynchronization therapy patients. Europace 2010; 12: 702-707.

40. Thomas SA, Friedmann E, Kao C, Inguito P, Metcalf M, Kelley FJ, Gottlieb SS. Quality of life and psychological status of patients with implantable cardioverter defibrillators. Am J Crit Care 2006; 15: 389-398.

41. Poole JE, Johnson GW, Hellkamp AS, Anderson J, Callans DJ, Raitt $\mathrm{MH}$, et al. Prognostic importance of defibrillator shocks in patients with heart failure. N Engl J Med 2008; 359: 1009-1017.
42. Sweeney MO, Ruetz LL, Belk P, Mullen TJ, Johnson JW, Sheldon T. Bradycardia pacing-induced short-long-short sequences at the onset of ventricular tachyarrhythmias: a possible mechanism of proarrhythmia? J Am Coll Cardiol 2007; 50: 614-622.

43. Taylor E, Berger R, Hummel JD, Dinerman JL, Kenknight B, Arria AM, et al. Analysis of the pattern of initiation of sustained ventricular arrhythmias in patients with implantable defibrillators. J Cardiovasc Electrophysiol 2000; 11: 719726.

44. Viskin S, Lesh MD, Eldar M, Fish R, Setbon I, Laniado S, Belhassen B. Mode of onset of malignant ventricular arrhythmias in idiopathic ventricular fibrillation. I Cardiovasc Electrophysiol 1997; 8: 1115-1120.

45. Thong T. Predicting imminent episodes of ventricular tachyarrhythmia--retrospective analysis of short R-R records from ICD. Conf Proc IEEE Eng Med Biol Soc 2008; 2008: 5664-5667.

46. Sandhu RK, Costantini O, Cummings JE, Poelzing S, Rosenbaum DS, Quan KJ. Intracardiac alternans compared to surface T-wave alternans as a predictor of ventricular arrhythmias in humans. Heart Rhythm 2008; 5: 1003-1008.

47. Swerdlow C, Chow T, Das M, Gillis AM, Zhou X, Abeyratne A, Ghanem RN. Intracardiac electrogram Twave alternans/variability increases before spontaneous ventricular tachyarrhythmias in implantable cardioverterdefibrillator patients: a prospective, multi-center study. Circulation 2011; 123: 1052-1060.

48. Grimm W, Christ M, Maisch B. Long runs of non-sustained ventricular tachycardia on 24-hour ambulatory electrocardiogram predict major arrhythmic events in patients with idiopathic dilated cardiomyopathy. Pacing Clin Electrophysiol 2005;28 Suppl 1: S207-10.

49. Wilkoff BL. The Dual Chamber and VVI Implantable Defibrillator (DAVID) Trial: rationale, design, results, clinical implications and lessons for future trials. Card Electrophysiol Rev 2003; 7: 468-472.

50. Kiès P, Bax JJ, Molhoek SG, Bleeker GB, Zeppenfeld K, Bootsma $\mathrm{M}$, et al. Effect of left ventricular remodeling after cardiac resynchronization therapy on frequency of ventricular arrhythmias. Am J Cardiol 2004; 94: 130-132.

51. Strohmer B, Mermi J, Castellanos E, Mayr H, Gill J, Abadia AA, et al. Impact of dual chamber pacing on the incidence of atrial and ventricular tachyarrhythmias in recipients of implantable cardioverter defibrillators. Pacing Clin Electrophysiol 2005; 28 Suppl 1: S249-54.

52. Viskin S, Glikson M, Fish R, Glick A, Copperman Y, Saxon LA. Rate smoothing with cardiac pacing for preventing torsade de pointes. Am J Cardiol 2000; 86: 111K-115K.

53. Friedman PA, Jalal S, Kaufman S, Villareal R, Brown S, Hahn SJ, Lerew DR. Effects of a rate smoothing algorithm for prevention of ventricular arrhythmias: results of the Ventricular Arrhythmia Suppression Trial (VAST). Heart Rhythm 2006; 3: 573-580. 